\title{
Feasibility of using ATP as an index for environmental stress on hermatypic coral
}

\author{
Lee-Shing Fang, Yan-Wan Chen, Chji-Shiarng Chen \\ Department of Marine Resources, National Sun Yat-sen University, Kaohsiung, 80424, Taiwan, Republic of China
}

\begin{abstract}
One of the most difficult problems for coral conservation is to find a sensitive physiological parameter to assess the health of living coral. In searching for a suitable index. ATP concentration in several species of coral under different natural and experimental conditions was studied from 1986 to 1989 in the coastal waters of southern Taiwan $\left(21^{\circ} 56^{\prime} \mathrm{N}, 120^{\circ} 44^{\prime} \mathrm{E}\right)$. Interspecific variation in ATP concentration in 6 coral species ranged from $8.2 \pm 1.3$ to $52.6 \pm 14.8 \mu \mathrm{g} \mathrm{g}^{-1}$. In an experiment of shortterm desiccation stress, ATP content in Acropora hyacinthus dropped drastically from $67.0 \pm 13.7$ to $7.9 \pm 6.1 \mu \mathrm{g} \mathrm{g}^{-1}$ During a bleaching event resulting from a natural disturbance, ATP concentration in $A$. hyacinthus dropped significantly but recovered gradually to normal values several months later. An annual survey of ATP variation in A. formosa showed a high peak between December and April with lower values in other months, perhaps in response to fluctuating temperature. In view of the significant rapid response of coral ATP content to stress and the rise in concentration during a recovery phase of months, the amount of ATP in living coral could be a feasible parameter for monitoring environmental stress in living coral.
\end{abstract}

\section{INTRODUCTION}

The survival and stability of coral communities world-wide are threatened by a variety of man-made or natural disturbances such as sewage discharge (Walker \& Ormond 1982), pollution (Fishelson 1973), siltation (Cortes \& Risk 1985), heated effluent (Jokiel \& Coles 1974), salinity change (Goreau 1964) and UV penetration (Harriott 1985). Awareness of most of these impacts came only after massive damage was observed in corals under a particular stress.

In a stony coral colony, the weight ratio between skeleton and biomass is higher than 99:1 and there is very little living tissue for physiological biochemistry analysis. Therefore, when monitoring the condition of a coral community, macro-scale methods such as visual census, growth rate, areal coverage comparisons, and species diversity changes are often used (UNESCO 1984). However, data collected by these methods are relatively subjective, often influenced by the background and underwater experience of the diver. Sometimes several years of work are needed to confirm a chronic change.

Recently, a method to measure the amount of ATP in coral was developed (Fang et al. 1987). ATP content has been shown to be a good parameter to estimate living biomass and cellular activity of many organisms (Holm-Hansen 1969, Sikora et al. 1977. Hunter \& Edward 1981, Maranda \& Lacroix 1983, Cole 1984). It was suggested that this parameter can also be used as a sensitive physiological index to reflect the vitality or health of living coral (Fang et al. 1987, 1989). However, extensive background data are necessary before a novel concept can be evaluated for practical usage.

This preliminary study was undertaken to establish the feasibility of using ATP concentration in living coral tissue as an index of environmental stress. We first examined interspecific variation of ATP content in 6 dominant local coral species in southern Taiwan. Then, a controlled desiccation experiment was performed to see how a short-term stress might influence the amount of ATP in living coral. Coincidentally, in July 1987, a mass bleaching of coral occurred near a nuclear power plant in the study area due to a combination of hot weather, spring low tide, and thermal effluent. This event provided an opportunity to examine the ATP concentration in coral colonies under stress and to track their recovery under natural conditions. Finally, we monitored the fluctuation of concentration of ATP in a single species during an annual cycle to understand seasonal rhythms. 


\section{MATERIALS AND METHODS}

Study area. Coral samples were taken from the west side of Nan-wan Bay $\left(21^{\circ} 56^{\prime} \mathrm{N}, 120^{\circ} 44^{\prime} \mathrm{E}\right)$ in southern Taiwan. The average water temperature at this subtropical site during winter is about $26.5^{\circ} \mathrm{C}$, and during summer is $30.5^{\circ} \mathrm{C}$ (Fig. 1). A nuclear power plant on the

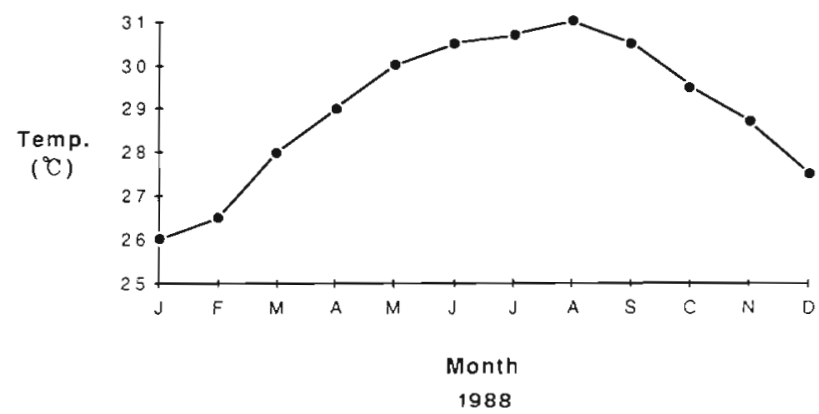

Fig. 1. Average monthly water temperature in the surveyed area in Nan-wan Bay of southern Taiwan

bay shore causes periodic temperature fluctuations. Samples were taken from 2 to $6 \mathrm{~m}$ deep, where the total areal coverage of coral was estimated to be 60 to $80 \%$. Acropora, Montipora, Pocillopora, Porites, Leptoria, Millepora and Lobophyton were the most abundant genera. Approximately 1 or 2 times per year summer typhoons randomly disturb this area. The annual range of salinity of the survey area was between 33 and $35 \%$, $\mathrm{pH} 8.1$ to 8.4, and dissolved oxygen 5 to $6 \mathrm{mg} \mathrm{l}^{-1}$, all normal values for seawater in the vicinity.

Sampling technique. A single colony of branching coral consists of up to hundreds of small branches, each composed of hundreds of individual polyps. Therefore, 2 types of sampling methods were employed. First, a single branch was taken from a colony and several colonies of the same species were sampled. The result would reflect the general ATP status of this coral in an area. Second, several branches were taken from one colony at each sampling time and the whole colony was monitored for a period of time. Since it is known that the physiological status of individual branches is not the same (Oliver 1984, Rinkevich \& Loya 1984), the branches were also regarded as independent samples. However, because all individual polyps on branches of one colony derived from the same genotype, repetitive samples from the colony showed how ATP concentration of this coral responded to environmental change with time.

Interspecific variation of ATP content. Small branches or pieces of hermatypic coral, weighing 5 to $10 \mathrm{~g}$, were taken from living colonies of 6 species (Table 1) by SCUBA divers using bone scissors. For each species,
6 to 15 colonies were haphazardly sampled. Samples of the same coral species growing at 2 different sites (A and B) ca $1 \mathrm{~km}$ apart were taken. Samples were stored in liquid nitrogen as soon as possible after collection and returned to the laboratory for analysis. This procedure allowed an assessment of the general ATP status of the common species in the area.

Short-term stress on ATP content. To monitor changes in ATP in coral under short-term stress, 7 colonies of Acropora hyacinthus were first measured for their ATP concentration. The colonies were exposed to air for $30 \mathrm{~min}$ and resampled for their ATP concentration. For each colony, 5 replicate measures were made by taking 5 branches.

Natural disturbance of ATP content. On July 8, 1987, a heat wave lasting $3 \mathrm{~d}$ hit the area. This, together with a low spring tide and a seasonal southwest wind that pushed the thermal effluent of the power plant near shore, resulted in a bleaching event in the coral community around Site B. Daytime air temperature was $37^{\circ} \mathrm{C}$ during these days, while water temperature reached $34^{\circ} \mathrm{C}$. This provided a rare opportunity to monitor ATP in coral under severely disturbed conditions with defined sources. We studied 4 out of the few colonies of Acropora hyacinthus that survived the bleaching event and tracked their recovery status for 122 d. Usually, 5 or 6 branches from one colony were measured at each sampling time.

Annual/seasonal variation of ATP content. To determine annual/seasonal variation in coral, ATP in branches from 4 colonies of Acropora formosa were randomly sampled periodically for $1 \mathrm{yr}$. At each sampling date, 5 or 6 branches were measured from each colony. A. formosa was chosen because it was the only species present with large enough colonies to provide the more than 150 samples needed during the year.

Measurement of ATP in coral. ATP in corals was extracted with $\mathrm{H}_{2} \mathrm{SO}_{4}\left(0.6 \mathrm{~N}, 4^{\circ} \mathrm{C}\right)$ and measured using a luciferin-luciferase fluorescence reaction kit (Lumac Environmental Application) in a biocounter (Model 2010A, Lumac/3M, the Netherlands) as described by Fang et al. (1987, 1989). Water temperature, salinity, $\mathrm{pH}$ and dissolved oxygen were recorded throughout the experimental period

\section{RESULTS}

\section{Interspecific variation}

The ATP content in surveyed coral species ranged from $8.2 \pm 1.3$ to $52.6 \pm 14.8 \mu \mathrm{g} \mathrm{g}^{-1}$ (Table 1). Lowest values were found in Montipora aequituserculata and highest values in Acropora hyacinthus. Different species of Acropora ranged from a low of $9.0 \pm 1.7 \mu \mathrm{g}$ 
Table 1. Interspecific variation of ATP concentration $\left(\mu \mathrm{g} \mathrm{g}^{-1}\right)$ in coral species. Number in parentheses is the number of colonies measured. Sites A and B were ca $1 \mathrm{~km}$ apart

\begin{tabular}{|lcc|}
\hline Species & Site A & Site B \\
\hline Acropora hyacinthus & $47.2 \pm 14.1$ & $52.6 \pm 14.8$ \\
Acropora tenuis & $(9)$ & $(15)$ \\
& $17.0 \pm 7.7$ & $23.5 \pm 15.8$ \\
Acropora aspera & $(6)$ & $(6)$ \\
& - & $9.0 \pm 1.7$ \\
Acropora formosa & - & $(10)$ \\
Montipora aequituserculata & $9.4 \pm 2.8$ & $8.2 \pm 1.3$ \\
& $(9)$ & $(9)$ \\
Porites nigrescens & $36.7 \pm 2.3$ & - \\
& $(7)$ & \\
& &
\end{tabular}

Table 2. Acropora hyacinthus. ATP concentration $\left(\mu \mathrm{g} \mathrm{g}^{-1}\right)$ in control (no stress) and stress (exposed to air for $30 \mathrm{~min}$ ) conditions. Each value represents the average of 5 measurements. Significance was examined by Student $t$-test, $\cdot \mathrm{p}<0.01$

\begin{tabular}{|ccc|}
\hline No. & No stress & Stress \\
\hline 1 & 82.5 & 13.9 \\
2 & 69.8 & 17.9 \\
3 & 62.4 & 5.0 \\
4 & 65.3 & 1.9 \\
5 & 70.3 & 2.9 \\
6 & 78.6 & 9.7 \\
7 & 40.4 & 3.8 \\
Mean \pm SD & $67 \pm 13.7$ & $7.9 \pm 6.1$ \\
t-test & \multicolumn{2}{c}{$10.4^{\circ}$} \\
\hline
\end{tabular}

$\mathrm{g}^{-1}$ in $A$. aspera to a high of $52.6 \pm 14.8 \mu \mathrm{g} \mathrm{g}^{-1}$ in $A$. hyacinthus. Between-site variations were generally smaller than between-species variations.

\section{Short-term stress}

The amount of ATP dropped drastically during the desiccation experiments with Acropora hyacinthus (Table 2). The change was unanimous in all samples and was statistically significant, indicating a very rapid and sensitive response in this species to stress.

\section{Natural disturbance}

There was a consistent trend of increasing ATP over the $122 \mathrm{~d}$ studied in all 4 colonies of Acropora hyacinthus that recovered from the bleaching event (Fig. 2; A1 to A4). The increasing concentration of ATP in each colony varied but generally agreed with divers' visual

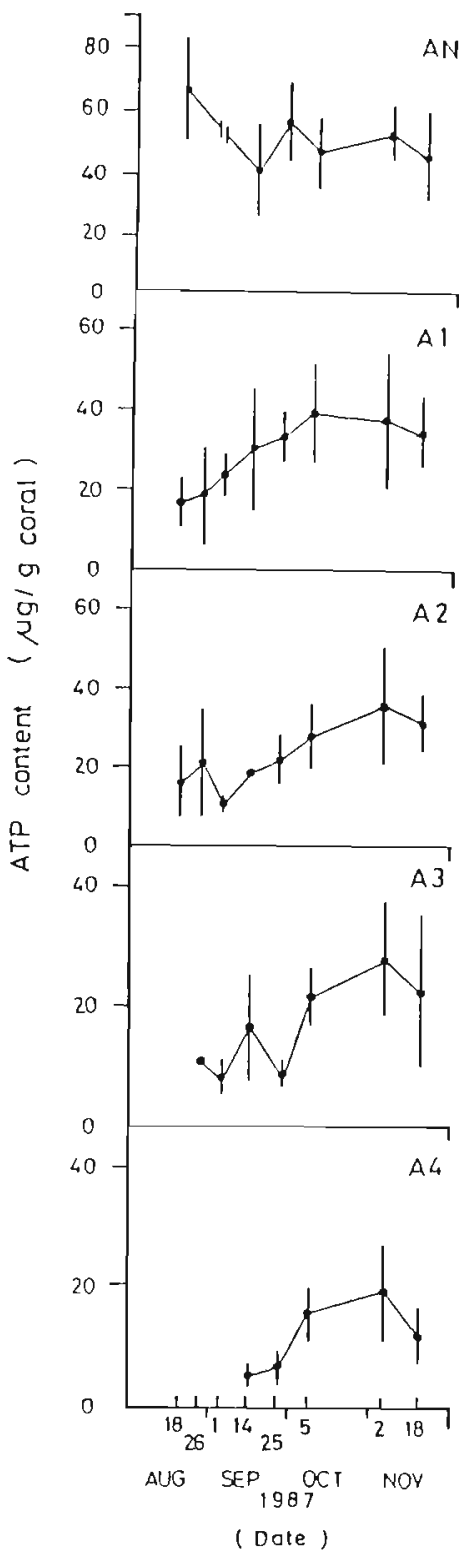

Fig. 2. Acropora hyacinthus. Changes in ATP concentration $\left(\mu \mathrm{g} \mathrm{g}^{-1}\right)$ after a bleaching event. A1 to $\mathrm{A} 4$ : bleached colonies; AN: normal colony as a control. Vertical bars are standard deviations

observations of recovery, i.e. a colony with rapidly increasing ATP also recovered to normal coloration more quickly. Monitoring had to be stopped due to bad ocean conditions in winter. By then, ATP concentration in the severely stressed colonies A3 and A4 still had not reached control level (Table 3 ).

\section{Annual/seasonal variation}

Annual fluctuations of ATP in Acropora formosa were similar between monitored colonies (Fig. 3). A general peak occurred from December to April. Annual 
Table 3. Significance test (Student $t$-test, $p<0.05$ ) of ATP concentration between control colony (AN) and bleached colonies (A1 to A4) in different months. "Significant difference. ns: not significant

\begin{tabular}{|llcccc|}
\hline $\begin{array}{l}\text { Control } \\
\text { colony }\end{array}$ & Month & \multicolumn{4}{c}{ Bleaching colony } \\
AN & & A1 & A2 & A3 & A4 \\
\hline \multirow{2}{*}{$\begin{array}{l}\text { Aug-Sep } \\
\text { Nov }\end{array}$} & $\cdot$ & ns & ns & ns & $\cdot$ \\
& & & & & $\cdot$ \\
\hline
\end{tabular}

low values of ATP occurred during August to October. However, in colonies F1 to F3, a small peak was recorded in July-August 1988.

\section{DISCUSSION}

\section{Interspecific variation}

In the 6 coral species surveyed (Table 1), ATP concentration differed by a factor of 7 . Yet, for any given species sampled at 2 sites, mean values were similar. It seems that values vary from species to species, but within species there is less variation at different sites. The growth habitat, depth and water quality of Sites A and $B$ were almost the same. Therefore, interspecific variation of ATP concentration in coral was considerable.

\section{Short-term stress}

The use of ATP as an indication of health of living coral could provide a way of assessing coral stress before permanent damage occurs. The quick, sensitive and drastic depression of ATP in the short-term stress experiment (Table 2) supports the utility of ATP as a stress indicator. ATP content is a valid estimate of living matter and is a key factor in energy change ratios of cell vitality (Karl et al. 1978, Maranda \& Lacroix 1983). The successful application of it in coral could greatly reduce the time and labour needed for a conventional community index of stress.

\section{Natural disturbance}

The high variance of data in the bleach-recovery colony could result from intra-colony variation of different branches (Oliver 1984). It was quite clear that the average concentration of ATP dropped to a relatively low concentration $\left(<20 \mu \mathrm{g} \mathrm{g}^{-1}\right)$ in the 4 bleached but then recovered colonies ( $A 1$ to $A 4$ ), when compared to the non-bleached colony $\left(A N,>40 \mu \mathrm{g} \mathrm{g}^{-1}\right.$ ) (Table 3 ). In

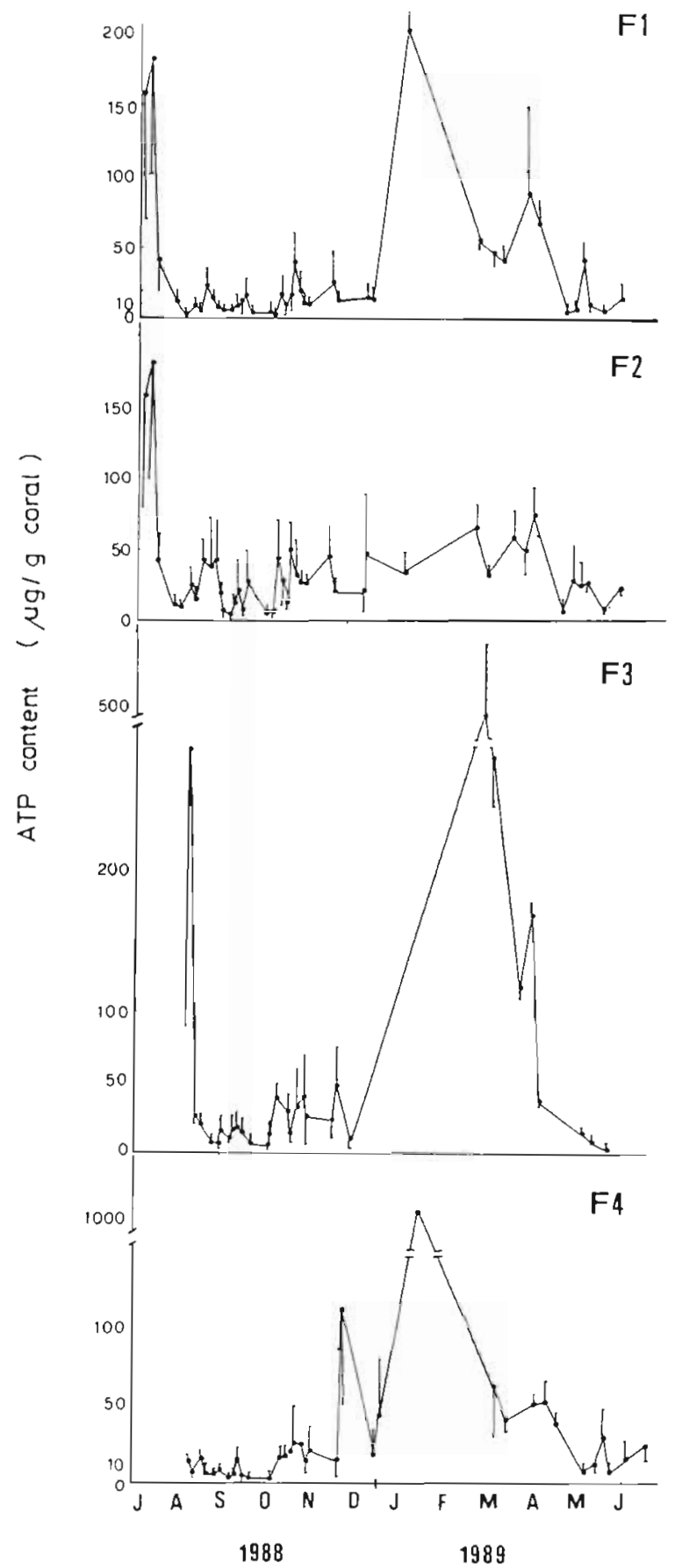

Fig. 3. Acropora formosa. Annual fluctuation of ATP. Four colonies (F1 to F4) were monitored. Vertical bars are standard deviations

fact, colonies A3 and particularly A4 were bleached so badly that we thought they would not recover. Therefore, samples of these two were not taken until 1 or 2 mo later when signs of coloration indicated their revival. Their ATP concentration rose from such a low level that the axis scale in Fig. 2 had to be marked differently to show their recovery. 
Statistically speaking, the overall data (August to November) of colonies A 1 to A3 were not significantly different from that of AN. Only A4 showed a significant difference. This was due to the high standard deviations. However, if we compare AN data for August to $A 1$ and $A 2$, and $A N$ data for September to $A 3$ and $A 4$, it is clear that ATP concentration in most of bleached colonies was significantly lower than that of the control colony (Table 3). The difference between AN and A3 was not statistically significant because of the high variation of data collected in that month. On the other hand, if the winter data for November of AN was compared with $\mathrm{A} 1$ to $\mathrm{A} 4$, it could be seen that ATP concentrations of A1 and A2 were back to normal, while A3 and A4 were still significantly lower. The mean value of ATP concentration in all these monitored colonies showed a depression in November. A similar phenomenon was also observed in the Acropora formosa colonies studied for seasonal variation. We can offer no good explanation at present.

Colonies with a fast recovery rate of ATP generally regained their coloration rapidly. However, after the middle of September no further deepening of the color of the once-bleached colonies (A1, A2) was detectable by divers although the concentration of ATP had not returned to its normal value and was still rising. The same phenomenon occurred in colonies A3 and A4 in November, suggesting that even if the appearance of a coral is normal, it may be physiologically stressed.

\section{Annual/seasonal variation}

The annual fluctuation of ATP in Acropora formosa was fairly consistent among the monitored colonies during the survey period (July 1988 to June 1989). From a long-term view point, one large peak of ATP could be recognized between late December and middle-April. A small sharp peak appeared in 3 colonies during July. Annual water temperatures (Fig. 1) showed temperature was fairly moderate $\left(26\right.$ to $28^{\circ} \mathrm{C}$ ) between December and April. From May to September temperature was over $30^{\circ} \mathrm{C}$. This implies that the best coral conditions in the surveyed area were during late winter to spring when water temperature was moderate. The high ATP value could come from cell activity of both coral cells and zooxanthellae in the polyp. Fang et al. (1987) demonstrated a positive correlation between ATP and chlorophyll a of zooxanthellae. Therefore, the ATP measured here represents the value of the whole symbiotic system.

\section{General remarks}

The high standard deviation of data from all the experiments reflects the lability of ATP during extrac- tion. For example, an ATP reading would drop to onetenth of its normal value if a sample was thawed in air and then put into $\mathrm{H}_{2} \mathrm{SO}_{4}$ for extraction, rather than being thawed directly in $\mathrm{H}_{2} \mathrm{SO}_{4}$. It is extremely important that sampling should minimize handling stress before freezing in liquid nitrogen, and the process of extraction and measurement of ATP should be as quick as possible. Moreover, samples from an individual branch, even on a single colony, may have different physiological condition due to the availability of light, oxygen, nutrients and other factors (Oliver 1984, Fang et al. 1989). All these can result in high fluctuations of ATP content in individual branches. Organisms such as copepods or bacteria associated with corals may also affect ATP in different seasons, environmental conditions and coral species. These were not investigated, but need to be examined in future work.

Despite the fact that the factors which could influence the ATP content of coral still await elucidation, the use of ATP as a parameter to diagnose the health condition of living coral seemingly can provide a way to assess coral stress before real damage is visible. Based on the analyses of at least 1047 branch samples in this study, we feel ATP content is a sensitive parameter. The sampling process caused very little damage to the coral. An ordinary technician can perform the analysis routinely and express the survey results in simple, comparable and standardized scientific units. There is no doubt, as indicated by the present data (Table 1, Fig. 3), that the natural rhythm and variation of ATP in different coral species needs to be further investigated. Yet the trend of change of ATP in living coral is correlated with the health condition of coral (Table 2, Fig. 2). Therefore, it is suggested that further study of ATP concentration might help establish an early-warning system' for use by those interested in coral management and conservation.

Acknowledgements. We thank Mr R. J. Hwang, Radiation Laboratory of Taiwan Power Company, and National Kenting Park for helping conducting the study, Miss Shuang-Hua Yu and Ya-Yin You for preparing the manuscript and Dr J. L. Simon for patient editorial assistance. This research was supported by National Science Council, ROC, NSC 77 to 79-0209B110-01 to Dr L.-S. Fang

\section{LITERATURE CITED}

Cole, B. E. (1984). Evaluation of an ATP photometer for measuring ${ }^{14} \mathrm{C}$ activity. Limnol. Oceanogr. 29: 663-666

Cortes, J., Risk, M. J. (1985). A reef under siltation stress: Cahuita, Costa Rica. Bull. mar. Sci. 36: 339-356

Fang, L. S., Chen, Y. W. J., Soong, K. Y. (1987), Methodology and measurement of ATP in coral. Bull. mar. Sci. 41: $605-610$ 
Fang, L. S., Chen, Y. W. J., Chen, C. S. (1989). Why does the white tip of stony coral grow so fast without zooxanthellae? Mar. Biol. 103: 359-363

Fishelson, L. (1973). Ecology of coral reefs in the Gulf of Aqaba (Red Sea) influenced by pollution. Oecologia (Berl.) 12: $55-67$

Goreau, T. F. (1964). Mass expulsion of zooxanthellae from Jamaican reef communities after Hurricane Flora. Science 145: 383-386

Harriott, V. J. (1985). Mortality rates of scleractinian corals before and during a mass bleaching event. Mar. Ecol. Prog. Ser. 21: 81-88

Holm-Hansen, O. (1969). Determination of microbial biomass in ocean profiles. Limnol. Oceanogr. 14: 740-747

Hunter, B. L., Edward, A. L. (1981). ATP and chlorophyll a as estimators of phytoplankton carbon biomass. Limnol. Oceanogr. 26: 944-956

Jokiel, P. L., Coles, S. L. (1974). Effects of heated effluent on hermatypic corals at Kahe Point, Oahu. Pacif. Sci. 28: 1-18

Karl, D. M., Jaugness, J. A., Cambell, L., Holm-Hansen, O. (1978). Adenine nucleotide extraction from multicellular organisms and beach sand: ATP recovery, energy charge

This article was submitted to the editor ratios and determination of carbon/ATP ratios. J. exp. mar Biol. Ecol. 34: 163-181

Maranda, Y., Lacroix, G. (1983). Temporal variability of zooplankton biomass (ATP content and dry weight) in the St. Lawrence estuary: advective phenomena during neap tide. Mar. Biol. 73: 247-255

Oliver, J. K. (1984). Intra-colony variation in the growth of Acropora formosa extension rate and skeletal structure of white (zooxanthellae-free) and brown-tipped branches. Coral Reefs 3: 139-147

Rinkevich, B., Loya, Y (1984). Does light enhance calcification in hermatypic coral? Mar. Biol 80: 1-6

Sikora, J. P., Sikora, W. B., Erkenbrecher, C. W., Coull, B. C. (1977). Significance of ATP, carbon, and caloric content of meiobenthic nematodes in partitioning benthic biomass. Mar. Biol. 44: 7-14

UNESCO (1984). Comparing coral reef survey methods. UNESCO Rep. marine. Sci. 21, UNESCO, Paris

Walker, D. I., Ormond, R. F. G. (1982). Coral death from sewage and phosphate pollution at Aqaba, Red Sea. Mar Pollut. Bull. 13: 21-25

Manuscript first received: July 19,1990

Revised version accepted: January 11, 1991 